\title{
Targeting astrocytes, a preventive strategy for diabetic complication?
}

\author{
Kee-Chan Ahn ${ }^{1,2}$ and Mee-Sook Song ${ }^{3 *}$ \\ ${ }^{1}$ Neurochemical Research Unit, University of Alberta, Canada \\ ${ }^{2}$ Envirobrain, Edmonton, AB, Canada \\ ${ }^{3}$ Department of Biological Sciences, Dankook University, Cheonan, South Korea
}

About $12 \sim 13 \%$ of total population aged over 65 and $50 \%$ aged over $85 \%$ and older has been affected by Alzheimer's disease(AD), and this tendency is continually increasing due to the expanded life span of humanity [1]. Using genetic animal models, AD have been intensively studied; however, more than $95 \%$ of all cases are sporadic, which is currently less understood because of multiple influences of genes, environments and aging. It is of interest that age-related metabolic disorders including diabetes, high blood pressure and stroke have a high incidence to develop $\mathrm{AD}$, suggesting there might be share mechanisms in the aforementioned metabolic diseases and $\mathrm{AD}[2,3]$.

Evidence in impaired cerebrovasculature have been reported in AD brains such as decreased micro vessel, damaged endothelial cells and pericytes of the vessel, downregulation of glucose transporters at the blood brain barrier(BBB), vascular accumulation of $A \beta$ and the associated activation of microglia and astrocytes surrounding the degenerating vascular endothelial cells $[4,5]$. More than $70 \%$ of $\mathrm{AD}$ subjects show cerebral amyloid angiopathy, which narrow the vessels and reduce blood flow, possibly resulting in stroke with cognitive deficits [6]. This serial event of cerebrovascular dysfunction eventually leads to the breakdown of the $\mathrm{BBB}$ with a subsequent neurodegeneration and brain inflammation [7]. The BBB, a highly dedicated structure, maintains brain homeostasis by restricting the transport of macromolecules including microorganisms and toxic chemicals from systemic blood circulation [8]. The BBB consists of a continuous lining layer of vascular endothelial cells covered by processes of astrocytes and neurons that becomes a barrier between the brain and other part of body [9]. The permeability of molecules through the $\mathrm{BBB}$ is tightly regulated in healthy brains for brain homeostasis [10], however it could be progressively weaken by aging and certain pathologies, which may result in invasions of bacteria or viruses from other part of body [11,5]. The slight disruption of $\mathrm{BBB}$ may alter protein expression in the component cells of the $\mathrm{BBB}$ including astrocytes and vascular endothelial cells that eventually cause oxidative stress, neurodegeneration and brain inflammation $[12,13]$. On the other hand, $\mathrm{A} \beta$ peptide in the brain is removed through LRP-1, a receptor for apolipoprotein $E$ that clears out brain derived $A \beta$ and is expressed in astrocytes and vascular endothelial cells at the BBB [14]. All these studies suggest that $\mathrm{BBB}$ dysfunction seems to be a central part of $\mathrm{AD}$ development, leading to the onset of $\mathrm{AD}$ pathogenesis such as $A \beta$ accumulation and tau pathology.

Glucose, the primary energy source for the brain, is transported from systemic circulation into the brain through glucose transporters (GLUTs), in particular GLUT1, highly expressed in endothelial cells at the BBB. Thus, glucose uptake into the brain is extensively relies on the expression of GLUT-1 at the BBB [15]. The decrease of GLUT1 observed in early stages of $\mathrm{AD}$ brains could reduce glucose uptake into the brain, initiating neurodegeneration [16].

Astrocytes are star-shaped glial cells that comprise about $50 \%$ of brain cells and support neurons structurally, metabolically, and tropically. Astrocytes have been intensively studied last two decades manifesting their multifunctional capacities in addition to the supportive roles for neurons [17]. Astrocytes play essential roles in normal development of neurons for neurite growth and synaptic formation. They also behave a synaptic safeguard by up taking excessive glutamate and calcium from synaptic cleft and metabolizing glutamate to glutamine in astrocytes, the only cells that have glutamine synthase in the brain [17].

Activation of astrocytes called astrogliosis is a distinctive brain response to stress stimuli, which is evident in alteration of cellular morphology and function, accompanying with the upregulation of glial fibrillary acidic protein (GFAP). Reactive astrocytes lead to reduction of glutamate uptake, subsequent to excitotoxicity by excessive extracellular glutamates [18]. A recent study by our group demonstrates that astrocytes become reactive at the initiation stage of brain inflammation in response to the stress and keep brain homeostasis, however, chronic activation of astrocytes ultimately deteriorate themselves, although astrocytes are more resistant to brain stress stimuli compared to neurons [17].

Astrocytes play essential roles for immune response against brain stress by secreting inflammatory/anti-inflammatory factors and neurotoxic factors [19]. As mentioned above, astrocytes also undergo morphological changes, called astrogliosis, indicated by increased GFAP expression [17], often resulting in scar formation, common in many brain injuries. During chronic activation of astrocytes, reduced expression of LRP-1 in astrocytes possibly induces $A \beta$ accumulation in the brain when BBB impaired [14]. It is known that $A \beta$ clearance through LRP-1 at the BBB was impaired in a diabetic animal model as a result of a decrease of LRP-1 expression [20]. The prolonged activation of astrocytes in a diabetic complication could initiate BBB dysfunction and further trigger the onset of AD pathologies. Thus, reactive astrocytes could be a therapeutic target in treating diabetic complication and delaying the development of $\mathrm{AD}$.

${ }^{\star}$ Correspondence to: Mee-Sook Song, Department of Biological Sciences, Dankook University, Cheonan, South Korea, Tel: 41-550-3066, E-mail: mssong@dankook.ac.kr

Received: July 26, 2018; Accepted: August 02, 2018; Published: August 04, 2018 


\section{Acknowledgment}

This work was supported by a research fund from Envirobrain and Dankook University. We acknowledge Jung H. Ahn for correcting grammatical errors in the manuscript. M.S. Song is currently an assistant professor in the Department of Biological Sciences, Dankook University (DKU). K.C. Ahn is a Chief researcher at Envirobrain.

\section{References}

1. Alzheimer Association (2012) Alzheimer's disease facts and figures. Alzheimers Dementia 8: 131-168

2. Luchsinger JA, Tang MX, Shea S, Mayeux R (2004) Hyperinsulinemia and risk of Alzheimer disease. Neurology 63: 1187-1192. [Crossref]

3. Mattson MP (2004) Pathways towards and away from Alzheimer's disease. Nature 430: 631-639. [Crossref]

4. Farkas E, Luiten PG (2001) Cerebral microvascular pathology in aging and Alzheimer's disease. Prog Neurobiol 64: 575-611. [Crossref]

5. Ahn KC, Learman CR, Dunbar GL, Maiti P, Jang WC, et al. (2018) Characterization of impaired cerebrovascular structure in app/ps1 mouse brains. Neuroscience 10:246-254

6. Smith EE, Greenberg SM (2009) Beta-amyloid, blood vessels, and brain function. Stroke 40: 2601-2606. [Crossref]

7. Moser KV, Humpel C (2007) Blood-derived serum albumin contributes to neurodegeneration via astroglial stress fiber formation. Pharmacology 80: 286-292. [Crossref]

8. Hawkins BT, Davis TP (2005) The blood-brain barrier/neurovascular unit in health and disease. Pharmacol Rev 57: 173-185. [Crossref]

9. Abbott NJ (2013) Blood-brain barrier structure and function and the challenges for CNS drug delivery. J Inherit Metab Dis 36: 437-449. [Crossref]
10. Abbott NJ, Rönnbäck L, Hansson E (2006) Astrocyte-endothelial interactions at the blood-brain barrier. Nat Rev Neurosci 7: 41-53. [Crossref]

11. Ujiie M, Dickstein DL, Carlow DA, Jefferies WA (2003) Blood-brain barrier permeability precedes senile plaque formation in an Alzheimer disease model. Microcirculation 10: 463-470.

12. Lam V, Hackett M, Takechi R, et al. (2016) Antioxidants and dementia risk consideration through a cerebrovascular perspective. Nutrients 8. [Crossref]

13. Erickson MA, Dohi K, Banks WA (2012) Neuroinflammation: a common pathway in CNS diseases as mediated at the blood-brain barrier. Neuroimmunomodulation 19: 121130. [Crossref]

14. Jaeger S, Pietrzik CU (2008) Functional role of lipoprotein receptors in Alzheimer's disease. Curr Alzheimer Res 5: 15-25. [Crossref]

15. Allen A, Messier C (2013) Plastic changes in the astrocyte GLUT1 glucose transporter and beta-tubulin microtubule protein following voluntary exercise in mice. Behav Brain Res 240: 95-102. [Crossref]

16. Winkler EA, Nishida Y, Sagare AP, et al. (2015) GLUT1 reductions exacerbate Alzheimer's disease vasculo-neuronal dysfunction and degeneration. Nat Neurosci 18: 521-530. [Crossref]

17. Song MS, Learman CR, Ahn KC, Baker GB, Kippe J, et al. (2015) In vitro validation of effects of BDNF-expressing mesenchymal stem cells on neurodegeneration in primary cultured neurons of APP/PS1 mice. Neuroscience 307: 37-50 [Crossref]

18. Cullen KM, Kocsi Z, Stone J (2006) Microvascular pathology in the aging human brain: evidence that senile plaques are sites of microhaemorrhages. Neurobiol Aging $27: 1786-1796$

19. Neal M, Richardson JR2 (2018) Epigenetic regulation of astrocyte function in neuroinflammation and neurodegeneration. Biochim Biophys Acta 1864: 432-443. [Crossref]

20. Ma LY, Fei YL, Wang XY, Wu SD, Du JH, et al. (2017) The research on the relationship of RAGE, LRP-1, and A $\hat{I}^{2}$ Accumulation in the hippocampus, prefrontal lobe, and amygdala of STZ-Induced Diabetic Rats. J Mol Neurosci 62: 1-10. [Crossref]

Copyright: (C2018 Kee-Chan A. This is an open-access article distributed under the terms of the Creative Commons Attribution License, which permits unrestricted use, distribution, and reproduction in any medium, provided the original author and source are credited. 